\title{
Investigating the Structural Relationship of Innovation Culture with the Educational Performance of Faculty Members in Lorestan University and Islamic Azad University, Khorramabad Branch
}

\author{
Azita sattar, PhD student (corresponding author) \\ Educational Administration , University of Isfahan \\ E-mail: article.author365@gmail.com \\ Saeed Rajaeepour, Associate professor \\ Educational Administration, University of Isfahan \\ Ghorbanali salami, Associate professor \\ Educational Administration, University of Isfahan \\ Ahmad Abedi, Assistant professor \\ Educational Administration, University of Isfahan
}

Received: August 9, 2014 Accepted: September 19, 2016 Published: February 29, 2016

doi:10.5296/jet.v3i1.9196

URL: http://dx.doi.org/10.5296/jet.v3i1.9196

\begin{abstract}
The objective of the present study was to investigate the structural relationship of the innovation culture with the educational performance of faculty members in the universities of Khorramabad based on the ideas and attitudes of faculty members and students. The population of the study consists of all full-time official faculty members working in Khorramabad universities (Lorestan University and Islamic Azad University, Khorramabad Branch) and also all students of the above mentioned universities in the academic year 2012-2013. The sample of the study was selected using stratified random sampling proportionate to the population size of the universities. The sample of Lorestan University based on professors and students was equal as 106 participants for professors and 212 participants for students. In addition, the statistical sample of Islamic Azad University was equal as 67 participants for professors and 134 participants for students. The questionnaires were researcher-made and developed based on Likert scale. The reliabilities of both questionnaires based on Cronbach's alpha were respectively equal as 0.93 and 0.96 and the statistical tests employed in the research were Pearson correlation coefficient and structural equation modeling. In general, according to the findings of the research, based on Pearson
\end{abstract}


correlation coefficient, there was no significant correlation between none of the seven research hypotheses or in other words, between 7 components of innovation culture and the dimensions of educational performance of faculty members in $\mathrm{P}>0.05$. Finally, structural equation modeling indicates that innovation culture and its dimensions have no direct effect on the educational performance of faculty members.

Keywords: culture of innovation, educational performance, university, faculty members.

\section{Introduction}

In the present age, the system of higher education particularly universities are considered as the most evident example of cultural organizations. Cultural ground building along with changes can establish appropriate relationship with educational performance with changes in academic culture to innovationin such a way that it results in presenting products such as innovative and dynamic alumni through creating innovation and increasing it and creating knowledge and apprenticeship in professors. By human investment particularly professors who are the main part of universities, effective steps can be taken regarding creativity, innovation and flourishing of students, universities and welfare of societies. Therefore, regarding the importance of innovation in organizations and that culture has an important role in creating innovation and ideas as the culture of each organization, the change in organizational cultures particularly the change of academic culture into innovation culture which results in promotion of educational performance of universities particularly the professors who are the main elements of universitiesis a necessary issue. Therefore, regarding the importance of the above issues, a definition of innovation culture is presented.

Wieland (2006), in a study titled as "Innovation culture, technology policy and the uses of the history", defines innovation culture as a group, social, or organizational framework which perceives the channels of technological and economic changes and the strategies which are provided for encountering them. In addition, according to Allen (1994), As long as the culture dominating an organization does not change, the creation of leading new ideas will not wrap up because there is a high and significant correlation between culture of an organization and innovation in the organization.

On the other hand, regarding the fact that the quality of faculty members is among the cases that universities and institutes of higher education always consider as their own objectives and to achieve it, the appropriate and efficient system of evaluating the performance of faculty members is used. In addition, judging their capabilities, innovations, competencies and professional skills can have suggestions for improving the performance through the system of evaluation and validation of their professional skills. Furthermore, judging the quality of higher education is also employed (Eshaghi, Mohammadi, and Parand, 2008) because it is possible that with changing innovation culture into an academic culture, creating development and dynamicity in professors in the stage of innovation and creation of ideas, producing products such as innovative alumni, increasing the level of articles and knowledge creating gatherings, faculty members' educational performance increases at the level of students and creation of new ideas in line with the welfare of societies and universities. Cassio (1995), knows performance as accomplishing tasks and responsibilities which are 
burdened on the individuals by organizations. Ezzati (2012) and Sa'adat (2003) define the evaluation of faculty members' performance as covering the evaluation of what is obtained from the mode of doing the burdened tasks and responsibilities. It means that this evaluation covers the results of educational affairs (performance). From the viewpoint of Alaei (2010) surely the evaluation of professors' performance should be considered as the inseparable part of a dynamic, innovative and diligent educational system. In fact, evaluation of the above performance increase the educational system in line with the welfare of societies, which results form an innovative and dynamic culture in universities.

\subsection{Statement of the problem}

The present century is that of creating ideas and developing modern technologies in different fields for transformation and development through scientific training. The high importance of scientific development and growth in the new field result in qualitative and quantitative development of universities and institute of higher education. In this line, the improvement of the quality of educational performance in universities seems necessary. According to Movery (2004), the main task and function of universities in achieving economic-centered objectives and the national innovation system (culture) is to produce knowledge and training efficient and skillful human forces and transfer knowledge.

Furthermore, according toGhroun (1994), since faculty members are among the main elements of the structure of higher education, whose qualitative and quantitative decrease have direct effects on the performance of higher education system and since skilled human resources required by different sections are trained by the unit of higher education particularly universities, reinforcing and developing this section particularly faculty members is considered as the soul of higher education (Ejtehadi and Ghourchian, 2011). From Attarzadeh's viewpoint (2008), since universities are the camps of new and innovation, students' evaluation of professors' educational performance is an important element in relation with evaluating faculty members' educational performance (because evaluating professors is important as well). This is because the important role of students as creative, innovative, efficient and dynamic products in the form of active and intellectual elites depends on innovative and diligent faculty members and it results in the flourish of societies. In general, regarding the importance of innovation culture which has an effective role in the educational performance of faculty members by throwing creativity and innovation on them and also whilst the dimensions of innovation culture in universities are institutionalized through identifying the components of an innovative culture, in addition to creating competitive advantage, results in the promotion of professors' educational performance and the flourish of societies and universities (Shahin, 2010; and Saeedikia, 2009). Therefore, universities' efficiency building and thought bearing are in the domains of power, innovation, creativity and initiative which is in the capability of the compatibility of a culture. It means that the necessity of transformation, change and avoidance of stagnation of cultural system or in other words the change in academic culture is in line with innovation culture. This issue has a significant effect on the innovative educational performance of professors in universities and the welfare of societies (Attarzadeh, 2008). 
The aim of the present study is to investigate the structural relationship of innovation culture with educational performance of faculty members in Khorramabad universities. To reach the mentioned objective, the ideas ofDobni (2008) in the form of a model in whichfactors effective on innovation culture are identified are used. According to Dobni, innovation culture is a multi-dimensional concept which includes: innovative tendency, organizational sustainability, organizational learning, creativity and capability, competitiveness, value tendency and innovation environments, and most of innovations are stated in the form of behaviors or activities which at last result in a tangibleperformance or action (Dobni, 2008). In this study, the relationship of each of components of innovation culture with the faculty members' educational performance, i.e. curriculum design, teaching methods, and evaluation of educational performancecan be indicted (Shabani, 2012). While according to the figure 1of this research, it is assumed that there is a correlation between innovation culture in universities and its components with faculty members' educational performance and its factors. Regarding the mentioned issues, institutes of educational system particularly universities are considered as the highest centers of bearing thought and producing knowledge in societies. Therefore, faculty members are among the important and key elements of higher education structure whose qualitative and quantitative loss has a positive and significant effect on faculty members' educational performance.

Accordingly, professors have important tasks in three educational, research and presentation of specialist services. Each of these levels are separately defined. In general, professors' educational tasks are curriculum design, teaching methods and evaluation of educational performance (Shabani, 2012), while curriculum design indicates the prediction of all activities by which professors administer some test from students before presenting the courses. This matter causes the identification of learners' capabilities of the new course (Abdollahi, 2012). As a result, before presenting the new course, professors classify educational objectives or behaviors regarding the course type. Mostly, these classifications, according to Bloom's ideas, are in three cognitive, emotional and psycho-motor which considering the course type and its content, identifies behavioral objectives. Although these three domains are presented in all courses, the severity and weakness of some of these domains is to pay attention to the course type (Saif, 2012: 29-30).

In relation with teaching methods, there are different definitions in such a way that in Oxford Dictionary, method means particular way of doing something; therefore, by teaching method, it means the particular way of performing teaching process (Abdollahi, 2012). Teaching methods such as lectures, explanation, show, problem solving and etc. and for facilitation of applying teaching skills such as: Brainstorming techniques, team technique, practicing and role taking technique are presented.

But another important issue is that different kinds of evaluation of educational processes should be conducted by professors regarding the objective and time before teaching process (primary evaluation) or during teaching (evolutional evaluation) or after teaching (summative or final evaluation). Each of these evaluations, i.e. before teaching is related to identification of new course prerequisites and the skills related to the course itself and also during the teaching of a particular course, the level of learners' skills of the particular courses or the 
weaknesses and strengths of the learners and professors as well as necessary reformations. After each particular course, either in the form of mid-term exam or final exam, scoring the particular courses causes learners' promotion to upper classes. In fact, the mentioned evaluation enjoy a great value in promoting professors' educational performance and students' dynamicity and innovation (Saif, 2011: 18-19; Shabani, 2012: 342). However, evaluating professors' performance is conducted in different forms such as: faculty members' colleagues, alumni, students, universities' officials and the dean of the faculty (Canon and Newbell, 2009: 230). On the other hand, the research tasks of professors have a wide range. The research components in universities results in the promotion of professors and professors' educational tasks are inseparable part of the performance of universities and research services including professors' research and scientific works, presenting innovative and valuable artistic work, fellowships, conducting research projects, presenting articles and new books and etc.

In addition, another task of professors is their professional services which include: services related to educational department, professional activities, educational services and public services which finally are related to affairs such as coordination in headquarters and research affairs, the dynamicity of fairs and etc. (Mohammadi and Fathabadi, 2007).

From the perspective of different scholars such as Aultman (2006) evaluating professors by students is a valuable resource for feedback to professors in order to improve their teaching quality and it can be a proper opportunity for improving educational innovation and teaching methods. In general, since the task of universities is in three educational, research and presentation of specialist services levels, paying attention to them has a particular necessity. These three levels or tasks of faculty members which is the main key for universities are integrated and inseparable. However, specialist research and service after teaching and during teaching is the inseparable part of the performance of educational system and their roles are in basic and applied levels (Mohammadi and Fathabadi, 2007).

D' Brentani and kleinschmidt (2004) believe that the research indicates that organizational culture particularly innovation promotes the performance of organizations because innovation culture consists of values and features welcoming new ideas (Zhu, 2011).

Furst et al. (2007) conducted a research titled as "innovation in higher education" based on Baldrige model. The results of the study indicate that the four factors are involved in successfully managing innovations and changes by educational institutes: the consistent commitment and support of leaders and senior managers of organizations, systematic methods of planning, cooperative and accurate processes and efficient and multidimensional communications.

Dobni (2008), conducted a research titled as" Measuring innovation culture in organization: The development of a generalized innovation culture construct using exploratory Factor analysis", using an exploratory analysis and attained these findings that the criterion of innovation can be indicated using a structure which includes seven factors: innovation thriving, organizational learning, creativity and capability, the tendency of work market, value tendency and implementation environment. These seven factors are applied diagnostically. Finally, he concluded that more measures should be particularly assigned for 
evaluation criteria of innovation culture because this model presents a practical method for measuring innovation culture and can be applied primarily for creating the level of innovation culture.

Attarzadeh (2008) conducted a documentary analysis research titled as "university and innovation, functions and pathology". The findings of the research indicate that the functions of universities, in spite of a relatively long record in Iran, have not properly developed. In evaluating this inefficiency the mixture of two intellectualist and pragmatist approaches in higher education can be effective.

Saeedikia (2009) conducted a research titled as "encouraging innovation culture in organizations". The results of the date indicate that in line with institutionalizing innovation culture, we should know the elements of an innovation culture. Therefore, the method related to the changeof organizational culture into innovation culture, i.e. emphasis on leadership behavior as a vital factor, idea promoting and applying idea promoting, empowering, and confidence in the staff and accepting logically their mistakes should be particularly considered and applied.

Niknami and Hemmatpoor (2009) in a research titled as "investigating the role of organizational culture in innovation of faculty members of Islamic Azad University for presenting appropriate strategies" indicates that in line with the realization of innovation of faculty members of universities influenced by changing forces, they should change their organizational culture to be able to keep their leading role in the present world.

\subsection{Research conceptual model}

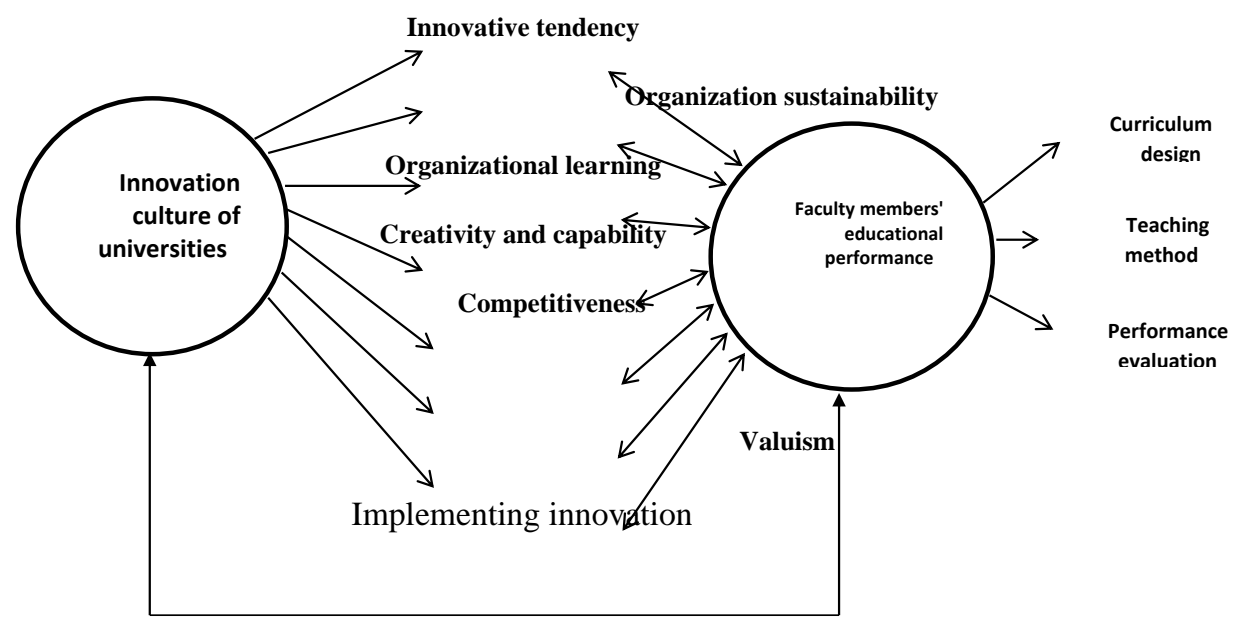

Figure 1. the conceptual model of the relationship of innovation culture and faculty members' educational performance

\section{Purpose of the study}

The general objective of the study is to investigate the structural relationship of innovation culture with the educational performance of faculty members in Khorramabad universities. 


\subsection{Research hypotheses}

The main hypothesis: there is a correlation between innovation culture in universities and its components and faculty members' educational performance and its dimensions.

Special hypotheses: there is a correlation between innovative tendency and faculty members' educational performance (curriculum design, teaching method, educational evaluation).

There is a correlation between organizational sustainability and faculty members' educational performance (curriculum design, teaching method, educational evaluation).

There is a correlation between organizational learning and faculty members' educational performance (curriculum design, teaching method, educational evaluation).

There is a correlation between creativity and capability and faculty members' educational performance (curriculum design, teaching method, and educational evaluation).

There is a correlation between competitiveness and faculty members' educational performance (curriculum design, teaching method, educational evaluation).

There is a correlation between value tendency and faculty members' educational performance (curriculum design, teaching method, educational evaluation).

There is a correlation between the environment of implementing innovation and faculty members' educational performance (curriculum design, teaching method, and educational evaluation).

\section{Methodology}

The method employed in the present study is descriptive-correlational. The population consists of all full time and official faculty members in Khorramabad University (Lorestan University and Islamic Azad University) as well as all students of the mentioned universities in the academic year 2012-2013. The sampling was conducted using stratified random sampling proportionate to the population of universities. The number of faculty members in Lorestan University was 220 individuals and the number of the students was 8000 individuals. In Islamic Azad University, there were 148 faculty members and 1400 students. Based on Morgan and Jersey table, the sample of Lorestan University proportionate to professors and students consists of 114 professors and 228 students respectively. But only 106 professors and 212 students responded the questionnaires. In addition, the sample of Islamic Azad University proportionate to professors and students consists of 75 professors and 150 students. But only 67 professors and 134 students responded the questionnaires.

\subsection{Data collection instrument}

Regarding the seven components of innovation culture, the questionnaire of organizational culture consists of 37 items and the questionnaire of faculty members' educational performance and evaluation consists of 23 items. The questionnaires are researcher-made and are developed based on a five-pointLikert scale. The reliability coefficient of both questionnaires were calculated using Cronbach's alpha to be 0.93 for innovation culture and 
0.96 for educational performance. It means that the reliability coefficient of the components of the questionnaires are at an acceptable level. The content validity coefficient of the questionnaire was investigated by experts and professors of management and educational management and their construct validity was conducted by exploratory (confirmatory) factor analysis. The validity coefficients of the two questionnaires were 0.656 and 0.734 respectively, i.e. the sample size enjoys a good sufficiency (proper for factor analysis). The statistical tests were employed for analyzing date: descriptive statistics (mean, SD) and inferential statistics (Pearson coefficient correlation and structural equation modeling.

\section{Results}

The first hypothesis: there is a correlation between innovative tendency and faculty members' educational performance (curriculum design, teaching method, educational evaluation). Regarding the obtained results, it is observed that there is no significant correlation between innovative tendency and faculty members' educational performance (curriculum design, teaching method, and educational evaluation) $(\mathrm{p}>0.05)$ (table 1).

The second hypothesis: there is a correlation between organizational sustainability and faculty members' educational performance (curriculum design, teaching method, educational evaluation). Regarding the obtained results, it is observed that there is no significant correlation between organizational sustainability and faculty members' educational performance (curriculum design, teaching method, and educational evaluation) $(\mathrm{p}>0.05)$ (table 2).

The third hypothesis: there is a correlation between organizational learning and faculty members' educational performance (curriculum design, teaching method, educational evaluation). Regarding the obtained results, it is observed that there is no significant correlation between organizational learning and faculty members' educational performance (curriculum design, teaching method, and educational evaluation) ( $\mathrm{p}>0.05)$ (table 3).

The fourth hypothesis: there is a correlation between creativity and capability and faculty members' educational performance (curriculum design, teaching method, and educational evaluation). Regarding the obtained results, it is observed that there is no significant correlation between creativity and capability and faculty members' educational performance (curriculum design, teaching method, and educational evaluation) $(\mathrm{p}>0.05)$ (table 4).

The fifth hypothesis: there is a correlation between competitiveness and faculty members' educational performance (curriculum design, teaching method, and educational evaluation). Regarding the obtained results, it is observed that there is no significant correlation between competitiveness and faculty members' educational performance (curriculum design, teaching method, and educational evaluation) $(\mathrm{p}>0.05)($ table 5).

The sixth hypothesis: there is a correlation between valuismand faculty members' educational performance (curriculum design, teaching method, and educational evaluation). Regarding the obtained results, it is observed that there is no significant correlation between valuismand faculty members' educational performance (curriculum design, teaching method, and educational evaluation) $(\mathrm{p}>0.05)$ (table 6). 


\section{Macrothink}

The seventh hypothesis: there is a correlation between innovation implementation and faculty members' educational performance (curriculum design, teaching method, and educational evaluation). Regarding the obtained results, it is observed that there is no significant correlation between innovation implementation and faculty members' educational performance (curriculum design, teaching method, and educational evaluation) $(\mathrm{p}>0.05)$ (table 7).

\subsection{General hypothesis}

The results obtained from the research hypotheses indicate that there is no significant correlation between seven components of innovation culture and dimensions of faculty members' educational performance because the value $\mathrm{p}$ is bigger than 0.05 .

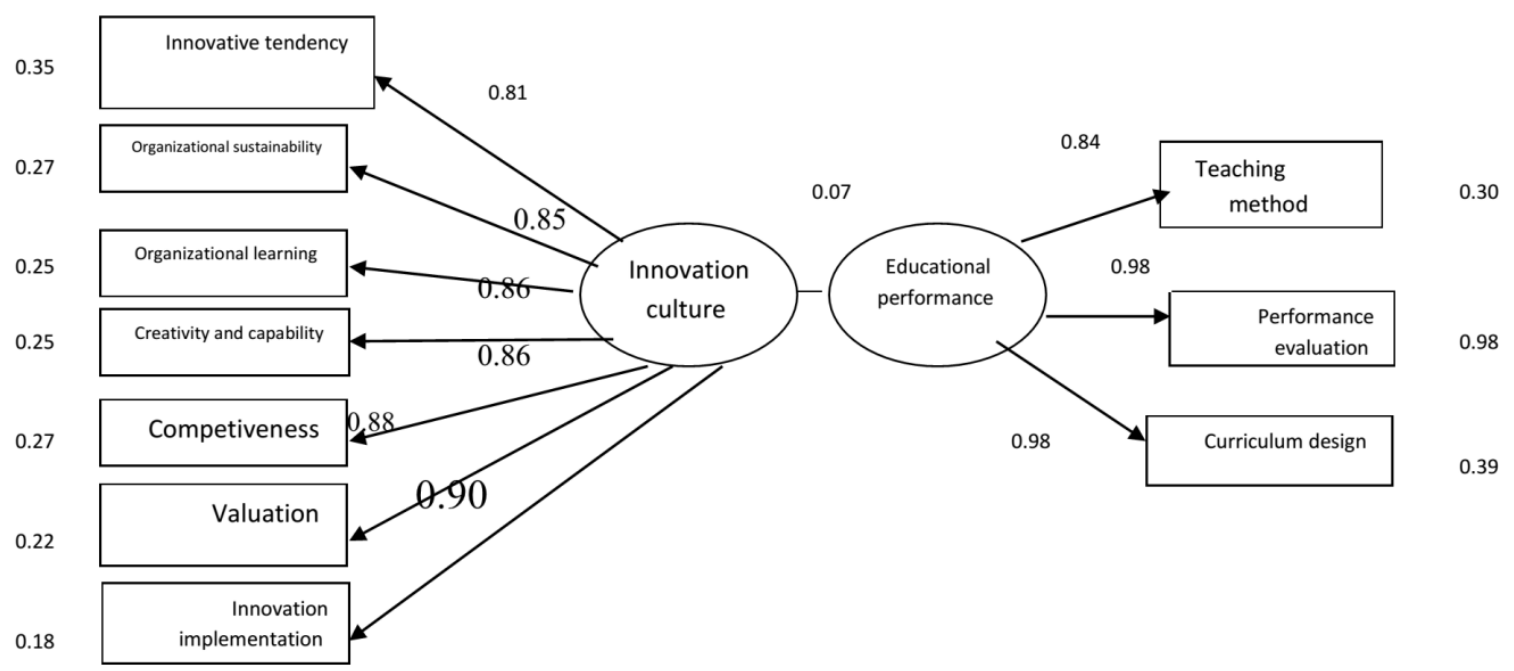

Figure 2. the available direct effects of path coefficients and their significance in the proposed model

The main hypothesis of the present study is that there is a correlation between universities' innovation culture and faculty members' educational performance and this relationships can be drawn in the form of a model. Based on this model, universities' innovation culture has a direct effect on faculty members' educational performance.

The production indices of the structural equation modelling is not dependent on general values, but the standard parameters $B$ and their correspondent values $T$ have gamma coefficients for each of the causal paths of exogenous variables of universities' innovation culture to endogenous variables of faculty members' educational performance. These coefficients and indices indicate the relative strength of each path. The coefficients $y$ are standardized regressions and their values should be between 0 and 1 . The path gamma coefficient (y) of universities' innovation culture on faculty members' educational 
performance equals as 0.07 , which is a positive and low path coefficient. However, the significant $t$-test indicates that this path is statistically significant $(t=0.94)(p>0.05)$.

\subsection{Findings}

The results obtained from the first hypothesis indicate that there is no significant correlation between innovative tendency and the total scale of faculty members' educational performance and its sub-components (curriculum design, teaching method, educational evaluation) $(\mathrm{p}>0.05)$. It means that Pearson correlation coefficient in correlation between innovative tendency and educational performance equaled 0.045 and its significance level was 0.55 . These figures show that there is no significant correlation between them because the value of significant level (p) is bigger than 0.05 .

The results obtained from the second hypothesis indicate that there is no significant correlation between organizational sustainability and the total scale of faculty members' educational performance and its sub-components (curriculum design, teaching method, educational evaluation) ( $\mathrm{p}>0.05$ ). It means that Pearson correlation coefficient in correlation between organizational sustainability and educational performance equaled 0.063 and its significance level was 0.41 . These figures show that there is no significant correlation between them because the value of significant level (p) is bigger than 0.05 .

The results obtained from the third hypothesis indicate that there is no significant correlation between organizational learning and the total scale of faculty members' educational performance and its sub-components (curriculum design, teaching method, educational evaluation) ( $\mathrm{p}>0.05)$. It means that Pearson correlation coefficient in correlation between organizational learning and educational performance equaled 0.032 and its significance level was 0.48 . These figures show that there is no significant correlation between them because the value of significant level (p) is bigger than 0.05 .

The results obtained from the fourth hypothesis indicate that there is no significant correlation between creativity and capability and the total scale of faculty members' educational performance and its sub-components (curriculum design, teaching method, educational evaluation) ( $\mathrm{p}>0.05$ ). It means that Pearson correlation coefficient in correlation between creativity and capability and educational performance equaled 0.003 and its significance level was 0.97 . These figures show that there is no significant correlation between them because the value of significant level (p) is bigger than 0.05 .

The results obtained from the fifth hypothesis indicate that there is no significant correlation between competiveness and the total scale of faculty members' educational performance and its sub-components (curriculum design, teaching method, educational evaluation) ( $p>0.05$ ). It means that Pearson correlation coefficient in correlation between competitiveness and educational performance equaled 0.07 and its significance level was 0.37 . These figures show that there is no significant correlation between them because the value of significant level (p) is bigger than 0.05 .

The results obtained from the sixth hypothesis indicate that there is no significant correlation between valuism and the total scale of faculty members' educational performance and its 
sub-components (curriculum design, teaching method, educational evaluation) $(\mathrm{p}>0.05)$. It means that Pearson correlation coefficient in correlation between valuism and educational performance equaled 0.04 and its significance level was 0.60 . These figures show that there is no significant correlation between them because the value of significant level ( $p$ ) is bigger than 0.05 .

The results obtained from the seventh hypothesis indicate that there is no significant correlation between innovation implementation and the total scale of faculty members' educational performance and its sub-components (curriculum design, teaching method, educational evaluation) ( $\mathrm{p}>0.05$ ). It means that Pearson correlation coefficient in correlation between innovation implementation and educational performance equaled 0.09 and its significance level was 0.22 . These figures show that there is no significant correlation between them because the value of significant level (p) is bigger than 0.05 .

As observed, the results obtained from the seventh hypothesis indicate that there is no significant correlation between seven components of innovation culture and the dimensions of faculty members' educational performance. Therefore, the consistency of the results of the present study with those of the conduced studies is investigated.

Corrca et.al (2007)in a study titled as "Leadership and organizational learning role on innovation and performance" concluded that these learning organizations such as universities support creativity and innovation through learning and result in creating new knowledge and ideas and increasing capability of understanding and applying it. In fact,generating learning, the improvement of organizational learning, is considered for fundamental innovation culture in products and processes. Therefore, paying attention to and supporting the tendency toward innovation in organizations particularly universities seems necessary through dynamic culture and innovation.

Some researchers such as Arad et al. (1997), in a research obtained these findings that evaluating ideas fairly is effective in supporting and encouraging creativity and the culture which supports consistent learning, by concentrating the existence of environment creating (curiosity), encouraging individuals to dialogue and debate, keeping knowledge and skills and updating them and learning skills of creative thinking are motivations for creativity and innovation.

Amabil (1995) and Tesluk et al. (1997), in their investigations obtained these findings that basic values, hypotheses and beliefs are reflected in the created forms of behaviors and activities assigned as management structures, policies, methods and procedures. This structure is effective on creativity in workplace based on direct learning. For example, by preparing the supportive resources in line with encouraging and developing new ideas, a supportive culture of innovative ways, presenting problems and finding their solution should be encouraged.

Arad et al. (1997), in another research obtained these results that some authors and also active individuals had identified the existence of cooperative teams in having effects on a degree of creativity and innovation in organizations. In fact, these work teams which accept the 
diversity of ideas and individuals' talent for complementing each other, cause promotion of creativity and innovation.

In a study, Shokri et al. (2009), investigating the role of learning in organizational innovation, concluded that organizational innovation and learning are primarily related to each other and learning in organizations particularly universities paves the path for the advent of innovation and consequently, the improvement of educational performance and competitive advantages. In addition, innovation results in the enrichment, promotion and updating of knowledge base in universities.

\section{References}

Abdollahi, H. (2012). In introduction to teaching methods, techniques and skills. Tehran: AllamehTabatabei University.

Alaei, M. (2010). A comparative investigation of the results of students' self-evaluation of the educational performance of faculty members of Ilam University of Medical Sciences. Journal of Ilam University of Medical Sciences, 18, 5-10.

Allen, T. (1994). People and technology transfer. International center for research of Manage of technology.

Amabile, T. M. (1995). Discovering the unknowable, managing the unmanageable. In C. M. Ford, \& D.A. (Eds.), creative Action in organization.

Arad. S., Hanson, M. A., \& Schneder, R. J. (1997). A Framework for the study of relationship between characteristic and organization. The Journal of creative Behavior.

Attarzadeh, M. (2008). University and innovation, functions and pathology. Islamic Azad University Journal, 12(4), 3-37.

Aultman L. P. (2006). An unexpected benefit of formative student evaluations. College teaching, 54(3), 251-8.

Bryan. (2001). Building the innovation Culture. Innovation Labs, LLC: 934.

Cassio, W. F. (1995). Managing human resource productivity of work life profits. London: McGraw Hill.

Connon, R., \& Newbell, D. (2009). The guidebook of improving teaching methods in universities and intitutes of higher education. In A. Nasr., H. Zareh, \& M. J. Pakseresht (Trans.). Isfahan: SAMT.

Corra, J. A., Morales, V. G., \&Pozo, E. (2007). Leadership and organizational learning role on innovation and performance. Journal of lesson from Spain Industrial Marketing Management, 36(10), 349-359.

Dobni, C. B. (2008). Measuring innovation culture in organization: The development of a generalized innovation culture construct using exploratory Factor analysis. European Journal of Innovation Management, 11, 539-559. 


\section{Macrothink}

Dobni, C. B. (2008). The DNA of innovation. Journal of Business Strategy, 29(2), 43-50.

Eshaghi, F., Mohammadi, R., \& Parand, K. (2008). The proper system of evaluating faculty members' educational performance. Tehran: Center for Educational Studies, Research and Evaluation. Year 1. No. 2.

Ezzati, M. (2012). Investigating the factors effective on educational performance of academic departments: a qualitative research. Quarterly Journal of Research and Planning in Higher Education, 18(3).

Furst-Bowe, J. A., \&Baucer, R. A. (2007), Application of the Baldrige Model for Innovation in Higher Education, New Directions For Higher Education, 137, 5-14.

Mohammadi, R. (2007). Evaluating quality in higher education.

Niknami, M. (2009). Investigating the role of organizational culture in innovation of the faculty members in Islamic Azad University for presenting proper strategies. Journal of Management and Work, 80, 103-114.

Sa'adat, E. (2003). Human Resources Management. Tehran: SAMT.

Saeedikia, M. (2009). The motivating innovation culture in organizations. Tadbir Journal. Institute for Humanities and Cultural Studies. Comprehensive Portal of Human Sciences. No. 209.

Saif, A. A. (2012). Measuring and evaluating in Educational Sciences. Tehran: Payam Noor University.

Shabani, H. (2012). Educational skills. Tehran: SAMT.

Shahin, A., \& SadeghBeig, A. (2010). Innovation management. Isfahan. Jihad Daneshgahi Publication.

Shokri, Z. (2009). The role of learning in organizational innovation. Tadbir Journal of Management, 212.

Tesluk, P. E, Faar, J. L., \& Klein, S. R. (1997). Influences of organizational culture and climate in individual creativity the Journal of creative Behavior, 31, 21.4.

Wieland, T. (2006). Innovation culture, technology policy and the uses of the history. International conference on innovation pressure 15-17 Germany March. Mumchen.

Zhu, C., \& Engels. (2002). Investigating Organizational culture and International Innovation in higher education. Educational Management Administration \& leader ship.

\section{Copyright Disclaimer}

Copyright reserved by the author(s).

This article is an open-access article distributed under the terms and conditions of the Creative Commons Attribution license (http://creativecommons.org/licenses/by/3.0/). 